\title{
Women's customer trusts in hospital's inpatient services
}

\author{
Cucu Zubaedah ${ }^{1 *}$, Popy Rufaidah², Dudi Aripin ${ }^{3}$, Sri Tjahajawati ${ }^{4}$ \\ ${ }^{1}$ Department of Dental Public Health, Faculty of Dentistry Universitas Padjadjaran, Indonesia \\ 2Department of Management, Faculty of Economy and Business Universitas Padjadjaran, Indonesia \\ ${ }^{3}$ Department of Conservative Dentistry, Faculty of Dentistry Universitas Padjadjaran, Indonesia \\ ${ }^{4}$ Department of Oral Biology, Faculty of Dentistry Universitas Padjadjaran, Indonesia
}

\begin{abstract}
Introduction: Customer trust is a tribute to officers or institutions performances and sacrifices. In the health marketing system, the relationship among health workers, doctors, patients or health service users is essential. The declining of women's health will have an impact on the overall life qualities of the community and eventually will decrease the Indonesian Human Development Index. The purpose of this research was to analyze the customer trust of women's inpatient in hospitals at West Java and determine the most influential dimensions and indicators of the women's inpatient customer trust. Methods: This research was explanatory research conducted with the survey method with the sample size of 398 respondents. The unit of analysis was a hospital in West Java, while the observation unit was the inpatient community group which considers inadequate and gets health financing subsidies from the government in 42 hospitals from 28 cities or regencies in the West Java provinces. The sampling method was multistage sampling and the research tool was a questionnaire. Customer trust variable had two dimensions: honesty and benevolence; each with five indicators. The statistical analysis method used in this research was the Wilcoxon test and partial least square test. Results: Both dimensions were dominant in measuring the customer trust variables with loading factor values which relatively similar to 0.831 for benevolence and 0.831 for honesty. Hospital staff as a dominant indicator of benevolence, given the loading factor value at 0.819 and R2 value at 0.480 ; hospital staff with integrity as a dominant indicator for honesty, given the loading factor value at 0.825 and R2 value at 0.472 . Conclusion: Women's customer trust of inpatient services in hospitals at West Java is in good condition. Honesty and benevolence dimension also has the same value in measuring women's customer trust. The most dominant indicator in measuring the dimension of benevolence is hospital staff and hospital staff with integrity for the honesty dimension.
\end{abstract}

Keywords: Customer trust, women, inpatient service, hospital.

P-ISSN 1979-0201, e-ISSN 2549-6212; Available from: http://jurnal.unpad.ac.id/pjd/article/view/25135

DOI: 10.24198/pjd.vol31no3.25135

Submission: July 12, 2019; Accepted: Nov 14, 2019; Published online: Nov 30, 2019

"Corresponding author: Cucu Zubaedah, Department of Public Health, Faculty of Dentisry Universitas Padjadjaran, Indonesia. Jalan Sekeloa Selatan I, West Java, Indonesia, 40132. Phone: +6281321940771; Email: cucu.zubaedah@fkg.unpad.ac.id 


\section{INTRODUCTION}

High health care costs can cause a person to bankruptcy. The amount of a heavy burden that poor people bear, especially women, makes them destitute and worsening their condition. These situations have resulted in the decrease of public health status. It is measured by five indicators which are infant mortality rate, underfive mortality rate, maternal mortality rate, crude death rate, and life expectancy rate. ${ }^{1}$ The declining of women's health will have an impact on the overall life qualities of the community and eventually will decrease the Indonesian Human Development Index.

The low level of health is a measure of the low quality of life. The low quality of life cannot be separated from the low of health service coverage. The lack of health care availability is influenced by socio-economic problems (in per capita income, education, health behaviours), government policies, payment mechanisms, health organisations, environmental and public trust in the health services. ${ }^{2}$ Improving health services based on human resources and the quality of health providers in the hospital is a priority of health programs.

Good interaction between the providers of health services with users will make the experience spreads. Users will get experience and benefit from the hospital services. Moreover, market-ing relation has been recommended as an essential strategic way for companies, especially the hospitals, for a better position, for those in the market and to engage further. Any complaint from a patient will be granted if such interaction has come to an end between the user as a recipient of the service and the hospital as a service provider. Public trust in the hospital for health care will give such benefit and welfare to its employees and also assist the government in empowering the community.

To improve the quality of medical services, the healthcare personnel (doctors and nurses) have to be eligible to the standards of the profession as regulated, pronouncing that health workers should "respect the rights of patients" and "asking for approval for any medical procedure to undergo". ${ }^{3}$ This professional standard underlying a service-oriented satisfaction and trust of users or patients.

Indonesia Human Development Index for 2014 reached 0.734 with medium category while the life expectancy of Indonesian society in 2015 was 70.1 years, the sixth highest in the ASEAN region. ${ }^{4}$ To improve the Indonesian Human Development Index, the government, in this case, the Ministry of Health implements health programs that care for the poor.

Life expectancy in West Java is 67.46 years; the infant mortality rate is 4.19 per 1,000 live births; mortality rate of under-fives is 4.39 per 1000 live births: maternal mortality rate is 73 per 100,000 live births. ${ }^{5}$ The number of babies born in Indonesia in 2015 is 33,278 cases. The number was decreased into 32,007 cases in 2016 . The number of mortality rate in 2016 has also been decreased into 4912 cases as previously in 4999 cases in 2015. Indonesia is a country with high in-fant mortality and maternal mortality. ${ }^{6}$ West Java Province is the province closest to the national capital, and one of the factors that influence the health status of the people of West Java is the adequate service provided by the health service centre.

To improve the health status of the Indonesian community, the Ministry of Health since 2005 proclaimed Healthy Indonesia 2025. The program has vision "Health is one of the elements of a prosperous Indonesian society, namely the achievement of the right to a healthy life for all levels of society, through a health system that can guarantee the protection of society from a variety of risks that can affect health quality, affordable health care services and equitable of health care services. $^{7}$

Health as an investment will result in a healthy and productive population as a resource for sustainable development and global competitiveness". ${ }^{7}$ Based on the foundation of Health Development and the manifestation of Healthy Indonesia 2025, the goal of health development to be achieved by 2025 is the increase in public health status, which is increasing life expectancy from 69 years in 2005 to 73.7 years in 2025. ${ }^{7}$ The implementation of the National Health Insurance for women and the poor is to have access to health services by obtaining health financing subsidies. 
Customer trust is key to the mechanisms of interpersonal relationship formation and development. ${ }^{8}$ Trust as a foundation of an interpersonal relationship is a prerequisite for cooperation and stability relation in institutions and markets. Customer trust is a tribute to officers or institutions performances and sacrifices. In the health marketing system, the relationship among health workers, especially between doctors and patients or health service users is essential. The relationship is indicated by the interaction between doctor and patient. This interaction helps to build user's trust in their doctors and the quality of medical services provided by the service provider. ${ }^{9}$ The result of the interaction between the doctor as a service provider with a patient (user) creates value simultaneously, which influence the user's trust. Customer trust will be built if the process of interaction between organisations and consumers; both of them are trying to create value that automatically provides benefits. The customer's trust is not easy to get, because in every interaction or transaction between the organisation and the customer is not always generating value. Grayson ${ }^{10}$ stated that inpatient users believe that a hospital as an exchange partner is generous and honest because they are based on direct observation, information received from external sources or processes that can be summarised varyingly.

Patients or inpatient users observation towards the hospital creates customer trust. Benevolence is referred to as extra-contractual behaviours of a contact person that assist clients for enhancing the well-being of the later ${ }^{11}$; it means that benevolence can improve happiness. Honesty is also mentioned as an essential component of palliative care, and it is important to clarify the meaning of this concept in relation to nursing. Staats ${ }^{12}$ suggested that honesty is one of the core values when talking about ethical behaviour. Honesty as a general component of heroism because honesty diminishes one's ability to neutralise or deny the undesirable aspect of one's behavioural or inaction, which is crucial in acting heroically. Honesty is the standard of human dignity.

The quality of healthcare is an issue that is continuously increasing. Health care affects the quality of life more than any other service sectors. ${ }^{13}$ Health care is a service with a high trust level known for its uncertainties and risks. Patients or their families (users) do not have the expert knowledge to assess the quality of service provided during the act of serving and even after receiving the service. Users assess the quality of health care services based on their interaction or known as the service meeting with health care providers; their doctor.

Doctor's behaviour is an instrument to create effective relationships with patients and would increase patients' trust with the service provider; hospital. According to the Republic of Indonesia Health Law No. 44 of 2009 on Hospital, quoting: "Hospitals are organized on a foundation of Pancasila and value of humanity, ethics and professionalism, benefits, justice, equality and anti-discrimination, equity, patient protection, and safety, along with the social function." 14 Hospital, as one of the healthcare service subsystems, delivers public service in the form of services value, namely health care and administrative services. The value of services provided by hospitals supported by reliable human resources; medical staff, medical support staff, administrative staff, technology and adequate infrastructure. The purpose of this research was to analyze the customer trust of women's inpatient in hospitals at West Java and determine the most influential dimensions and indicators of the women's inpatient customer trust.

\section{METHODS}

This research was explanatory research conducted by survey method with a sample size of 1076 respondents. The unit of analysis was a hospital in West Java while the observation unit was inpatient community group which considers inadequate and gets health financing subsidies from the government. The inpatient community consists of 398 females in 42 hospitals from 28 cities or regencies in West Java province.

Customer trust variable has two dimensions which were honesty and benevolence. The dimension of honesty had several indicators including hospital staff that care about patient condition, hospital staff generosity to patient condition, hospital staff who always responsive and offer an explanation of the patient condition, and 
hospital staff who provides care guideline to the patient's condition. The dimension of benevolence had several indicators including reliable hospital staff, honest hospital staff, hospital staff which is open about patient condition, hospital staff whose understand the patient condition, and hospital staff with good integrity. The sampling method was multistage sampling and the research tool was a questionnaire. Primary data collected directly from the patients, patient families, or collective group.

The statistical analysis method used in this research were the Wilcoxon statistical test, and also validity and reliability test. Both of them were used to determine which dimension had the most crucial role in the user's trustworthiness, and to find which indicator had the most prominent role in that dimension.

To protect the basic rights and welfare of the subject of the health research and to assure that the research operates in accordance with ICH-GCP guidlines and other applicable laws and regulations, this research had thoroughly reviewed and approved by the Health Research Ethics Committee of Universitas Padjadjaran.

\section{RESULTS}

Customer trust was tested using the median test per sample by the Wilcoxon signed-rank test and assuming that the median for the medium and maximum score was 3.5. The hypothesis was $\mathrm{H}_{0}$ : Me $\leq 3.5$, Customer trust is low; $\mathrm{H}_{\mathrm{a}}$. Me $>3.5$, Customer trust is good. Based on the processing data concerning customer trust, the results acquired the value of estimated me-dian was 4.0 , with $p$-value $=0.001$. Because $p$-value $=0.001<0.05$, then a $5 \%$ error rate of $H_{0}$ was rejected and $\mathrm{H}_{\mathrm{a}}$ was accepted; therefore, it can be implied that the customer trust was good. Trust of inpatients at several hospitals was based on direct observation, outside source, or a particular process which can be concluded variationally in several hospitals in West Java. A "Good Grade" of customer trust is the result of the stakeholder's hard work, including the cooperation between the hospital management and customers. The health professional (doctors, nurses, pharmacist, etc.) are bounded by profession oath to not differ in the social status for patient care services.
Table 1. Customer trust using Wilcoxon signed-rank test

\begin{tabular}{|cccc|}
\hline \multicolumn{3}{|c|}{ Test of median $\leq 3.500$ vs. median $>3.500$} \\
\multicolumn{2}{|c|}{$\mathrm{N}$ for Wilcoxon } & \multicolumn{2}{c|}{ Estimated } \\
$\mathrm{N}$ & Test statistic & $\mathrm{P}$ & Median \\
398 & 34.567 & 0.001 & 4.000 \\
\hline
\end{tabular}

Customer or patient are also wanted to be treated humanely. If the customer is not well-treated by the hospital, the hospital will suffer the loss of customer trust. The patients or customers will think twice to revisit the same hospital. This is a bad precedent for the success and achievement of the improved health status of society. This condition will also result in the unsuccessful government health programs, as well as the achievement of improving the health status of Indonesian society that not yet achieved.

On the other hand, well-treated customers or inpatients will bring high customer trust. High customer trust in a particular hospital will make people commit to the hospital and recommend the hospital to other customers and the public. Customer trust is considered as an important variable to keep the relationship between hospital and customers and increasing relationship and reducing the perception of risk effectively. It is also a foundation of the inter-personal relationship as a condition to cooperate in the future and even as a foundation of stabilisation of involvement in the social institution and market competition. Table 2 presented the data that analysed based on the dimension. Based on Table 2, five indicators used to measure benevolence dimension have more loading factor than 0.5 , and $\mathrm{t}$-value that was higher than 1.96, and also closed to 1 coefficient reliability.

In conclusion, these indicators were considered to be valid and reliable in measuring the benevolence dimension. The most dominant indicator in measuring these dimensions was the "Hospital's officers", given 0.819 loading factor and $0.480 R^{2}$ value or in other words, $48.0 \%$ of respondents' variability of answer regarding the hospital's officers give steps of treatment regarding patients' condition (Z1.5) was influenced by the benevolence factor. Benevolence is fundamental in the loyalty-building process and the trust of the hospital's customer and also as an active indication about specific strategic communication of the hospital. As shown in Table 3, five indicators 
were used to measure the dimensions of honesty, with a loading factor value higher than 0.5 , $t$-value higher than 1.96, and reliability coefficient value closed to 1.

Table 2. Measurement model of benevolence dimension

\begin{tabular}{lccccc}
\hline \multicolumn{1}{c}{ Indicator } & Loading factor & $\mathrm{R}^{2}$ & $\mathrm{VE}$ & T-statistic & Note \\
\hline Hospital's officers have concern about our condition (customer) $\left(\mathrm{Z}_{1.1}\right)$ & 0.803 & 0.4480 .807 & 36.361 & Valid \\
Generous hospital staffs towards users/patients condition $\left(\mathrm{Z}_{1.2}\right)$ & 0.818 & 0.4510 .729 & 36.285 & Valid \\
$\begin{array}{l}\text { Hospital's officers are responsive/tolerant towards our condition (customer) } \\
\left(\mathrm{Z}_{1.3}\right)\end{array}$ & 0.796 & 0.3630 .782 & 40.134 & Valid \\
Hospital's officers give explanations about the patient condition $\left(\mathrm{Z}_{1.4}\right)$ & 0.802 & 0.3770 .848 & 40.032 & Valid \\
Hospital's officers give steps of treatment regarding patient's condition $\left(\mathrm{Z}_{1.5}\right)$ & 0.819 & 0.4800 .717 & 38.155 & Valid \\
Composite reliability & 0.840 & & Reliable \\
Variance extracted & 0.777 & & 0.840 & & Reliable \\
Cronbach's Alpha & & Reliable \\
\hline
\end{tabular}

Table 3. Measurement model of honesty $\left(Z_{2}\right)$

\begin{tabular}{lccccc}
\hline \multicolumn{1}{c}{ Indicator } & Loading factor & $\mathrm{R}^{2}$ & VE & T-statistic & Note \\
\hline Reliable hospital's officers $\left(\mathrm{Z}_{2.1}\right)$ & 0.797 & 0.463 & 0.345 & 36.227 & Valid \\
Reliable hospital's officers $\left(\mathrm{Z}_{2.2}\right)$ & 0.789 & 0.4470 .327 & 36.241 & Valid \\
Hospital's officers who has openness about patient condition $\left(\mathrm{Z}_{2.3}\right)$ & 0.778 & 0.3020 .300 & 41.123 & Valid \\
Hospital's officers who has understand patient condition $\left(\mathrm{Z}_{2.4}\right)$ & 0.787 & 0.4100 .282 & 36.567 & Valid \\
Hospital's officers who has integrity $\left(\mathrm{Z}_{2.5}\right)$ & 0.825 & 0.4720 .236 & 38.236 & Valid \\
Composite reliability & 0.840 & & & Reliable \\
Variance extracted & 0.702 & & & Reliable \\
Cronbach's Alpha & & 0.833 & & Reliable \\
\hline
\end{tabular}

All indicators considered to be valid and reliable to measure the dimension of honesty. The most dominant indicator was an officer who has integrity (Z2.5) with loading factor value at 0.825 and $\mathrm{R}^{2}$ value at 0.472 , or in other words, $47.2 \%$ of respondent's variability of answer about an officer in hospital $\left(\mathrm{Z}_{2.5}\right)$ was affected by honesty. Inpatients at several hospitals in West Java knew well the condition of other users medically and economically, and the officers handle patients professionally.

Customer trust variable measured with two dimensions. Both dimensions were dominant with loading factor value which relatively similar. Each dimension had a value of 0.831 for benevolence and 0.831 for honesty. Both dimension also had the same value in measuring customer trust.

Table 4 showed that the dimension of benevolence and honesty had relatively similar high value. Overall, inpatients of several hospitals in West Java make an inter-personal relationship with the hospital by being cooperative to make the treatment process going as expected. Hence there was a factor of benevolence and honesty given by the officers of several hospitals in West Java.

Table 4. Measurement model of customer trust $\left(\eta_{2}\right)$

\begin{tabular}{lccccc}
\hline \multicolumn{1}{c}{ Dimension } & Loading factor & $\mathrm{R}^{2}$ & $\mathrm{VE}$ & T-statistic & Note \\
\hline Benevolence $\left(\mathrm{Z}_{1}\right)$ & 0.876 & 0.654 & 0.070 & 44.508 & Valid \\
Honesty $\left(\mathrm{Z}_{2}\right)$ & 0.889 & 0.6612 & 0.072 & 49.386 & Valid \\
Composite reliability & 0.874 & & & & Reliable \\
Variance extracted & 0.823 & & & Reliable \\
Cronbach's Alpha & 0.895 & & & Reliable \\
\hline
\end{tabular}


Inpatients had a belief that the hospitals were generous, honest, in good quality, and good satisfaction. Benevolence given by several hospitals in West Java had a purpose of helping patients in solving problems. It also aimed to improve the quality of patient's life and motivate them to act based on greater public interest.

In the variable of customer trust, the dimensions of benevolence and honesty had a relatively similar high value. Patient/women's inpatient with limited socioeconomic status based on experience and observation during the hospitalisation process and inter-personal relationship with the hospital act cooperatively hence smoothen the inpatient's healthcare process. Limitations of this study was to exclude hospital personnel as research subjects.

\section{DISCUSSION}

High/good user trust is an invisible treasure for a hospital. Hospital personnel (doctors, nurses, midwives, pharmacists, etc.) are bound by the professional oath not to distinguish between social status for patient care services. Inpatient users have socio-economic limitations. Many users admit that it is the first time undergoing inpatient health care in the hospital. High user confidence in the hospital causes the patient/user to commit to the hospital and will recommend it to the public. Customer trust is considered to be essential in maintaining and improving relationships, and also reduce the perceived risks effectively. It is the foundation of interpersonal relationships as a prerequisite for subsequent cooperation as a basis for relationship stability in social institutions and market competition.

The benevolence the hospital provides is to assist patients/users in solving problems dealing with their health. It is a form of awareness/ response aimed at improving the patients/ users welfare, and being motivated to act for the greater public interest. Benevolence is very crucial to the process of building the loyalty and trust of hospital users and an active indication of the specific strategic communications of the hospital. Female inpatients/patients in the present study, who receive a minimum standard of care, which is class III treatment room facilities, assess that hospital staff with limited facilities and human resources have worked professionally with care and responsiveness to their problems. Life expectancy rate of Indonesians is increasing nowadays. Women become healthier and more empowered to make a more significant and better contribution to the health and well-being of families.

Hospital-patient honesty is an essential component of patient care in explaining the concepts about nursing: to help patients/users, to be forgiving, to tell the truth about the condition of the patient, and to act correctly on the patient's condition. Encouraging the patient to have a passion for healing against his or her suffering which is a reflection of the hospital's sense of responsibility to the patient/user to alleviate the pain.

The honesty that the hospital provides to the patient/user is part of the ethical virtue/ moral character of the hospital. The patient/user relationship with the hospital is facilitated by the belief that the hospital has a moral for honesty because honesty is the key to the establishment of human relationships. Patients/users of women's inpatients receive professional treatment from hospital staff in the form of benevolence. The hospital, in its service to the public, should not discriminate because of the patient's social status. In the view of patients/inpatients in the present study, hospital staff has worked and treated them regardless of social status.

Patients/inpatients have a belief that the hospital is generous, honest, in the expected quality, and good satisfaction. The benevolence and honesty the hospital provides are to assist patients/users in solving problems dealing with the health of the patient. It is a form of awareness that aims to improve the well-being of patients/women users and be motivated to act for the greater public interest thus can lead to declining of the infant and toddler mortality rates. Benevolence and honesty are vital to the process of building user loyalty and trust in hospital services and becoming an active indication of specific strategic communications in hospitals.

The benevolence and honesty provided by the hospital health officer in the inpatient care process become more valuable. Female users get value/ benefit due to savings in terms of time, cost, and effort. Patients are motivated to recover quickly 
so that the treatment period can become shorter. This situation has an impact on the operational expense of medication, accommodation, and other costs during the inpatient process in the hospital. While the hospital will be affected by the optimisation of the patient's bed. With a shorter treatment period, the patient's bed can be utilised by another patient, whether the patient gets a health-financing subsidy from the government as well as the general class III patient. The burden of the hospital's health workers work reduced as well as the self-satisfaction of hospital health personnel if the patient went home shorter in a state of recovery (better). Furthermore, efforts to accelerate the reduction of maternal mortality can be done by ensuring that every mother can access the qualified health services such as maternal health services, delivery assistance by trained health personnel, post-partum services for mothers and infants, special care and referral in case of complications, ease of getting maternity leave and childbirth, and family planning service. ${ }^{15}$ Women's customer trust in government-provided facilities especially for pregnant and mothers is expected to help the birth of a golden generation that will improve the health and quality of life of Indonesians.

\section{CONCLUSION}

Women's customer trust of inpatient services in hospitals at West Java is in good condition. Honesty and benevolence dimension also has the same value in measuring women's customer trust. The most dominant indicator in measuring the dimension of benevolence is hospital staff and hospital staff with integrity for the honesty dimension.

\section{REFERENCES}

1. Rothenberg R, Stauber C, Weaver S, Dai D, Prasad A, Kano M. Urban health indicators and indices--current status. BMC Public Health. 2015; 15: 494. DOI: 10.1186/s12889-0151827-x

2. Singh A, Purohit B. Dental public health! A mistaken identity. Acad Leadership. 2011; 9(2): 1-7.
3. The Republic of Indonesia Health Law No. 36 of 2009 concerning Health. Ministry of Health of The Republic of Indonesia. Jakarta; 2009. $1-48$.

4. Hidayangsih PS, Hapsari D, Ma'ruf NA. Formulation of Indonesian Public Health Development Index. Bul Penelitian Sist Kes. 2011; 14(2): 126-35.

5. Mizutani M, Tashiro J, Maftuhah. Health Needs Assessment for Health Promotion in an Indonesian District of West Java. J St Luke Nurs Soc. 2015; 18(2): 3-13.

6. Erlyana, Damrongplasit KK, Melnick G. Expanding health insurance to increase health care utilization: will it have different effects in rural vs. urban areas? Health Policy. 2011; 100(2-3): 273-81. DOI: 10.1016/j. healthpol.2010.11.008

7. Higashi MK. Working together to reduce maternal and infant mortality in Indonesia: the role of technology. Med J Ind. 2011; 20(4): 245-6.

8. Guenzi P, Georges L. Interpersonal trust in commercial relationships: Antecedents and consequences of customer trust in the salesperson. Eur J Market. 2010; 44(1-2): 114-38. DOI: 10.1108/03090561011008637

9. Gaur SS, Xu Y, Quazi A, Nandi S. Relational impact of service providers' interaction behavior in healthcare. Manag Serv Qual. 2011; 21(1): 67-87.

10. Grayson K, Johnson D, Chen DFR. Is Firm Trust Essential in a Trusted Environment? How Trust in the Business Context Influences Customers. J Mark Res. 2008; 45(2): 241-56. DOI: 10.1509/ jmkr.45.2.241

11. Nguyen N. Competence and benevolence of contact personnel in the perceived corporate reputation: An empirical study in financial services. Corp Reput Rev. 2010; 12(4): 345-56. DOI: $10.1057 / \mathrm{crr} .2009 .25$

12. Staats S, Hupp JM, Hagley AM. Honesty and heroes: A positive psychology view of heroism and academic honesty. J Psychol. 2008; 142(4): 357-72. DOI: 10.3200/JRLP.142.4.357372

13. Berry LL, Bendapudi N. Health care: A fertile field for service research. J 
Serv Res. 2007; 10(2): 111-22. DOI: 10.1177/1094670507306682

14. Ministry of Health of the Republic of Indonesia. Law Number 44 of 2009 on Hospital (State Gazette of the Republic of Indonesia of 2009 Number 153, Supplement to the State Gazette of the Republic of Indonesia Number 5072). Ministry of Health of The Republic of
Indonesia. Jakarta; 2009

15. Kaur J, Franzen SRP, Newton-Lewis T, Murphy G. Readiness of public health facilities to provide quality maternal and newborn care across the state of Bihar, India: a cross-sectional study of district hospitals and primary health centres. BMJ Open. 2019; 9(7): e028370. DOI: $10.1136 /$ bmjopen-2018-028370 